\title{
The reported speech evidential particle in Lamjung Yolmo
}

\author{
Lauren Gawne \\ SOAS, University of London
}

\begin{abstract}
Grammatically encoded evidentials that marks 'reported speech', 'hearsay' or 'quotation' are attested in languages from a variety of families, but often receive cursory description. In this paper I give a detailed account of the reported speech particle ló in Lamjung Yolmo, a Tibeto-Burman language of Nepal. This particle is used when the speaker is reporting previously communicated information. This information may be translated from another language, may be a non-verbal interaction turn or may have been an incomplete utterance. Speakers choose to use the reported speech particle in interaction, and the pragmatic effect is usually to add authority to the propositional content. Detailed description of the use of reported speech evidentials in interaction across different languages will provide a better understanding of the range of their function.
\end{abstract}

Keywords: evidentiality, reported speech, Tibeto-Burman

\section{Introduction}

Evidentiality is a well-attested feature of many languages, with typological work observing that there are many similarities in the categories found in these systems (Willett 1988; Aikhenvald 2004). One category that is often noted is 'reported speech', 'hearsay' or 'quotative'. Even in languages without a paradigmatic evidential system, quotative forms can occur, often through grammaticalization of verbs of saying (Aikhenvald 2004:271). Although these forms are often noted, they are rarely given a detailed description.

In this paper I provide a detailed account of the reported speech particle ló in Lamjung Yolmo (Tibeto-Burman), a Tibetic variety spoken in Nepal. By exploring its interactional function I will demonstrate that the nature of the 'speech' reported is a more broadly constructed interactional turn than a verbatim quotation of an original utterance. Lamjung Yolmo speakers also have a lexical verb with which 
they can mark reported speech events. The choice of the reported speech form in interaction also indicates that it serves to strengthen the authority regarding the information in the utterance. This pragmatic function is different to that which is often attested for reported evidentials, which are usually described as marking a 'weakening' the speakers epistemic certainty regarding the truth value of the propositional content (Aikhenvald 2004: 180).

Yolmo (ISO 639-3 scp) is a Tibetic language of the Tibeto-Burman family spoken in Nepal. There are a number of different varieties, with the main population residing in the Melamchi and Helambu valleys. There are isolated populations of 500-1000 speakers in Ilam, Lamjung and Ramechhap that were settled at least a century ago (Gawne 2013b). ${ }^{1}$ The Lamjung variety is spoken by around 700 people in half a dozen villages in the Lamjung district of Nepal, and is one of the more endangered variety of Yolmo. Like many Tibetic languages, Lamjung Yolmo has a set of evidential distinctions that are marked on copula verbs, and related verbal auxiliaries. The distinctions in Lamjung Yolmo include perceptual, egophoric and general fact, as well as a dubitative, which is an epistemic marker of reduced certainty. Table 1 gives a summary of the copular forms in Lamjung Yolmo, with the semantics along the top, and general syntactic distribution down the side. The forms inside the square are also found as auxiliaries in complex verb constructions.

Table 1. Copular verb distinctions in Lamjung Yolmo

\begin{tabular}{|c|c|c|c|c|}
\hline & Egophoric & Dubitative & $\begin{array}{c}\text { Perceptual } \\
\text { evidence }\end{array}$ & General fact \\
\hline \multirow[t]{2}{*}{ Equation } & yìmba & yìndo & (dùba) & - \\
\hline & mìn & mìndo & (mìnduba) & \\
\hline \multirow{4}{*}{$\begin{array}{l}\text { Existential } \\
\text { non-past: }\end{array}$} & yè & yèto & dù & ònge \\
\hline & \multirow[t]{2}{*}{ mè } & mèto & mìndu & mèonge \\
\hline & & & dùba & \\
\hline & & & mìnduba & \\
\hline \multirow[t]{2}{*}{ past: } & yèke yèba & & & \\
\hline & mèke mèba & & & \\
\hline
\end{tabular}

1. The Ramechhap community call themselves Kagate or Syuba and consider themselves closely related to Yolmo. Although their language has a distinct ISO 639-3 code (SYW) and is often treated as a separate language in the literature, it is largely mutually intelligible with Yolmo (Hari 2010:1). 
Although there are many grammatical contexts in which a form with evidential weight must be used, there are also grammatical contractions that do not require an evidential copula or auxiliary, such as simple present and past tense constructions. The language also has the reported speech particle, which is the topic of this paper. The RS particle is in a different syntactic position to the other evidential forms, and therefore can interact with them in a way that they cannot interact with each other. The RS particle can occur with all other evidential forms, and constructions that do not include any grammatical evidential form. The evidential in the embedded clause refers to the evidence used to make the original utterance, while the RS particle is used to refer to the evidence that the speaker. Tournadre and LaPolla (2014:241) separate a reported 'source' from sensory 'access' to information in their treatment of evidentiality. This is a useful conceptualisation, as it demonstrates the difference between the kinds of semantics found in the copular verb set and the semantics of the RS particle. In Lamjung Yolmo the two different types of evidence are found in different locations in the grammar, and can interact with each other. Therefore, the RS particle does not necessarily interact directly with the value of the evidential in the embedded utterance, although a study that presents a conversation analysis approach may demonstrate that speakers deliberately preference certain utterances with certain evidential weights to report. Such a analysis is outside of the scope of this paper. The RS particle is not obligatory, but is used in specific discourse contexts. See Gawne (2014) for a detailed description of the copula and auxiliary evidential forms.

Examples of Lamjung Yolmo used in this paper are drawn from a corpus of elicited and naturalistic data, archived with Paradisec. ${ }^{2}$ Each example includes a reference with the speaker initials and the archival file number of the recording, which is also the date. Naturalistic examples also include a time code. Where examples were from observed interactions that weren't recorded the notebook reference is given.

Eliciting evidential forms is useful for testing grammaticality and structural features, but does not demonstrate the range of interactional functions the particle may have. On the other hand, completely naturalistic data may not allow for a clear understanding of the nature of the original utterance that is being reported. This article draws on elicited and observed utterances, but also draws on structured interactional data, where the researcher provides the contextual frame through an open-ended task. This allows for the clear tracking of knowledge state for participants. In this paper I discuss examples drawn from a number of these tasks. The first is the game 'twenty questions' where one participant looks at an image of an item commonly found in the village and the other must ask yes/no

2. The collection can be viewed at catalog.paradisec.org.au/collections/LG1. 
questions to guess what the item is. The second is the Family Story task, a set of picture cards that participants must describe and then use to create a narrative of a family drama (described in San Roque et al. 2012). The third is a set of optical illusions that participants must describe together. The fourth is a task where participants listen with headphones to utterances from earlier recordings, and then answer the researcher when they ask a question like 'what did s/he say?' All of these methods are described in more detail in Gawne (2013a).

Before describing reported speech particles in Lamjung Yolmo(\$4), I discuss the nature of reported or quotative evidentials and their relationship to other evidential forms $(\$ 2)$. I also introduce the Lamjung Yolmo verb of saying (VoS), to demonstrate the differences with structures using the evidential particle $(\$ 3)$.

\section{Reported speech and evidentiality}

Reported speech is almost always included in typologies of evidential types (Aikhenvald 2004; Willett 1988; San Roque and Loughnane 2012). This category of evidentiality is found in many Tibeto-Burman languages, many languages of South America, and languages from Western Austronesia, North America and Australia, and even in language families or areas where there is not a high frequency of evidentiality. In languages that have only one evidential form, it is often the reported speech form (Aikhenvald 2004:31). Reported speech is worth investigating as an evidential form because it is interactionally complex, signalling the attribution of responsibility in discourse to another party (Ameka 2004: 8).

In this section I give a brief overview of the terminology used to discuss reported evidentiality. I then look at the description of reported speech in a variety of Tibeto-Burman languages, including those closely related to Lamjung Yolmo, providing context for the analysis in $\$ 4$. Finally, I look at the discussion of the stance-taking value of reported speech evidentiality, and how these forms are often described as a way of weakening epistemic authority.

The literature on reported speech refer to this category as 'reported speech', 'quotation' or 'hearsay'. Often these terms are used interchangeably, but examples of languages where more than one reported evidence form exists indicates that we should think of them as separate terms. For example, Central Pomo has two different evidential markers for reporting speech. Mithun (1999: 184) observes that "prototypical hearsay evidentials, which indicate verbal evidence from unspecified persons, are distinct from quotative makers used in citing the words of a specific speaker." This distinction is also made in Lepcha within the Tibeto-Burman family, with a hearsay mere and a quotative yang (Plaisier 2007: 137-138). Narua (Naic, also known as Yongning $\mathrm{Na}$ ) distinguishes between a reported form $t s i^{13}$ 
and quoted form $p i^{33}$. The quoted form specifically requires an overt indication of who the speaker is, while the reported does not (Lidz 2007:51, 53). These examples demonstrate the value of keeping these terms distinct. Quotative best describes a direct verbatim repetition of a specific speech event, with the original speaker overtly indicated or contextually clear (Aikhenvald 2004: 177). Hearsay is for the reporting of speech that may not have been a single original utterance, and cannot be directed to a single individual. As I demonstrate below reported speech sits somewhere between these two, when there is an original utterance, that may not be repeated verbatim, but which is from a single individual, even though they may not need to be overtly mentioned in the reporting. Because it sits somewhere between the two alternatives reported speech is also the term that I use to describe the general category of evidentiality that these are distinctions within.

These reported speech forms are most often clause-final particles or clitics. They do not take morphological marking and are often monosyllabic. These markers often have a different syntactic structure and pragmatic effect from constructions that use a verb of saying. Grammars I have surveyed often only include a short description of the reported speech marker in the section on evidentiality or clause-final particles, although sometimes they are just listed in a lexicon, or glossed in texts without description, particularly in older descriptive work.

Evidentiality is commonly attested in Tibeto-Burman languages, with many languages including a reported speech category. Matisoff (2003) reconstructs a 'quotative particle' $d z(y) a y><$ tsay for Proto-Tibeto-Burman. This form is unrelated to the Lamjung Yolmo form under discussion in this paper, however the inclusion of this form indicates that this grammatical feature has long been common to the area. This does not mean that all synchronic forms in the family are cognates or behave the same way.

Reported speech markers have a diverse range of forms, and are found in a diverse range of Tibeto-Burman languages including, but no means limited to, Galo (Tani) juu (Post 2007:631), Lahu (Lolo-Burmese) cê (Matisoff 1982:377380), Qiang (Qiangic) - $i$ (LaPolla \& Huang 2003: 204), Garo (Bodo-Garo) -na (Burling 1961:36), Dolakha Newar (Central Himalayan) hă (Genetti 2007:258) and Turung (Jingpho) ska (Morey 2010:458). Standard Tibetan na.re is used to introduce speech (Jäschke 1881; Simon 1968), however it is uncommon in a number of its features. Firstly, it precedes the quoted speech, instead of coming after it like all of the other attested particles. The second is that the name of the speaker is made clear, and when it is not, the speaker is clear from context. Simon (1968:557) argues that the role of this particle is to emphasise the speaker, as well as the spo- 
ken content. This is different to almost all other attested forms, where the original author of the utterance is rarely made clear. ${ }^{3}$

Within the Central Bodish group, many languages have cognate reported speech forms that occur after the reported content. Amdo Tibetan se (Sun 1993: 983), Central Tibetan -s (Zeisler 2004: 889), Drokpa Tibetan -s/sa (Caplow 2000) and Khams Tibetan -sa (Hongladarom 2007: 11-12) make one group, with those forms deriving from the Written Tibetan verb zer. Many other languages in this family use the form lo, including Balti (Zeisler 2004: 797), Dzongkha (Driem \& Tshering 1998:405), Jirel (Maibaum \& Strahm 1973), Kagate (Höhlig 1978), Kyirong (Huber 2005), Ladakhi (Zeisler 2004:797), Purik (Zeisler 2004:797) and Melamchi Valley Yolmo (Hari 2010:79-80). Huber (2005: 185) observes that Jäschke (1881) gives WT lo as a reported form, but indicates that it is mostly colloquial. This $/$ lo/ particle might be related to the verb $<$ zlo, bzlas $>$ 'to repeat', which is used to mean 'speak' in some Tibetic languages, such as like Cone (Jacques 2014: 346). ${ }^{4}$ Although the form is the same in all of these languages, it does not mean that it is used in the same way. As I demonstrate in the data analysis in $\$ 4$, the use of the reported speech particle in Lamjung Yolmo appears to be quite different to how the usage is described for Melamchi Valley Yolmo, a closely related variety.

In Melamchi Valley variety of Yolmo Hari (2010:79-80) observes that the form $l o$ is used to indicate "I heard somebody else say this." It follows a direct quote from the other speaker. Hari observes that the speaker will usually mention who the original author of the utterance was, although this is not the case for any examples she has in the grammar. Although she labels this a 'hearsay' particle, it appears from her description that it functions as what I am calling a quotative, as it relates to a single specific utterance from an individual, and is not used for vague, unattributable utterances. Looking at the examples of lo in Hari (2010), they all appear to be drawn from narratives, where they are used as a marker of that genre.

(1) tahybu tahybu 'azi 'nuhmukhun pins um 'du lo formerly formerly e.sister y.sister they sibling three exist.MIR RS 'Once upon a time there were three sisters.' (Hari 2010:65)

3. I am currently working on a project looking at RS particle forms across the Tibeto-Burman language. Data cited here are drawn from that study. Data from this study indicate that this is a common feature of Tibeto-Burman languages, but the form and function of these RS particles can vary between languages. Data collection has also demonstrated that these RS particle forms are often under-described, I hope that this current paper can offer insight into how we can better describe the use of RS evidential forms in Tibeto-Burman languages and more broadly.

4. I would like to thank one of the two reviewers of this paper for making this suggestion. 
Hari's (2010) description appears to be concordant with Höhlig's (1978:20) analysis of the closely related language Kagate, where lo is used when a person is "reporting what he has heard from an eyewitness [to the event being reported]":

(2) tiring Maila tom phre-si lo today Maila bear meet-completive.witnessed secondhand 'today Maila met a bear.' (Höhlig 1978:22)

Höhlig also observe that $l o$ is frequently used in narratives, where it most commonly occurs with $d u$, which she glosses as the 'completive, unwitnessed. ${ }^{5}$ Once the reported speech form has been used at the start of a story, or section, the storyteller does not need to keep using it.

Zeisler's (2012:889) discussion of the cognate lo in Ladakhi (West Tibetan) mentions that in the quoted speech the evidential value does not shift, but the pronoun does shift to reorient from the original speaker to the person now reporting. This indicates that evidential information is retained from the original utterance in at least one language related to Lamjung Yolmo. For some varieties where this form is noted, there is very little that describes its function. I hope that this paper can serve as a model for approaching the role of RS particles in Tibetic languages.

Although not a related language, it should be noted that Nepali (Indo-Aryan) also has a marker of reported speech. Peterson (2000:18) observes that the particle $r e$ "denotes that the speaker has his/her knowledge through another person." It's possible that the Nepali form was innovated due to ongoing contact with TibetoBurman languages. More work is needed on the interactional uses of the reported form in Nepali.

Reported speech evidentials may also have a pragmatic effect with regards to the speaker attitude towards the reported content. Chafe (1986) and Anderson (1986) discussed how the use of a reported speech evidential can allow speakers to distance themselves from the content or indicate that they are uncertain about the proposition in another person's speech (Aikhenvald 2004: 180). However this is only one possibility for how reported speech could be used, and it does not necessarily follow that reported constructions are markers of reliability (Mushin 2001:73).

Within Tibeto-Burman, discussion of reported speech forms does not often include discussion of pragmatic effects of their use. Watters's (2002:296-297) description of the Kham (Kham-Magar) hearsay particle di makes clear that use of it makes "no claim about the truth of the statement," although it does allow the

5. This form is cognate with a common perceptual evidential marker in Tibetic languages ('dug in Standard Tibetan), and therefore is likely not an 'unwitnessed' form. More work on Kagate evidentials needs to be completed. 
speaker to "disclaims responsibility" for the "apprehension of truths leading up to the conclusion." While this may be a fixed characteristic of the reported speech particle in Kham, and does not contain the specific attitude of a speaker, this element of "disclaiming responsibility" is a way in which a speaker could possibility indicate their attitude towards the information. Similar observations can be made about speakers' attitude towards the truth-value of the content of an utterance they mark with a reported evidential form. Daudey (2014:387) describes the Northern Pumi (Qiangic) hearsay marker as "speakers distance themselves from the making any truth-claim about what they are reporting." Sun (1993:983) observes that speakers of Amdo Tibetan (Central Tibetan) using a quotative evidential on an utterance are "uncommitted to its truthfulness." Finally Lee (2011:140-141) argues that the Eastern Tamang (West Bodish) reportative is used when "the speaker is not sure of the accuracy of the statement." All of these descriptions indicate that if there is any pragmatic effect it is of distancing the user from vouching for the truth of an utterance.

In one of the most detailed investigations of the use of reported speech evidentiality in interaction, Michael (2008, 2012, forthcoming) looks at Nanti, an Arawak language of the Amazon area. Nanti has both a lexical quotative structure and a grammaticalized quotative. While the grammaticalized form does not appear to have any specific pragmatic effect, the lexical quotative is used when the speaker is "committed to interactional force of utterance" (Michael 2012:321). While in this case it is the lexical verb, and not the grammaticalized evidential that bears this pragmatic feature, it illustrates that reporting other people's speech does not just have to be used as a distancing strategy in interaction. Similarly I demonstrate in $\$ 4.3$ that it is possible for a reported evidential form to also have this interactional effect.

\section{Verb of saying in Lamjung Yolmo}

As well as a reported speech particle, Lamjung Yolmo has a verb of saying (VoS) làp-. In this section I describe the basic features of the VoS so as to contrast it with utterances that us the RS particle. Lamjung Yolmo has SOV word order, with the VoS usually occurring after the reported content. In (2) the VoS is used in a direct speech structure. The reported speech is presented with no deictic shift from the original utterance (1). The first person pronoun remains, as does the tense and epistemic value of the copula. The agent in the matrix clause ( $y \grave{a}=k i$ nòmo=ki) is deictically oriented towards the person who reported the speech. The agents at both levels of the utterance in (2) share a referent, as shown in the subscript notation on the English translation. While direct speech reporting like this is possible, 
it is not the preferred structure with the VoS. The VoS can also be used with something that looks like indirect reported speech as well (3). In this example we see that there are no longer two overt referents. Instead, only the referent that is deictically oriented to the person reporting the speech remains. The epistemic value of the copula form, however, always remains as it was in the original utterance. ${ }^{6}$ Bracketing for (5) is actually quite difficult as nòmo is not necessarily a feature in the complement clause. Nor is it necessarily a part of the matrix clause; note the lack of ergative. Ergative marking in Yolmo, like in Tibetan (Tournadre 1991) is not obligatory, but occurs due to a range of pragmatic factors. One factor that may be influencing the lack of ergative here is the fact that nomo is not exclusively the agent of the matric clause.

(3) yà nà-ti yè

1sg be.ill-PFV COP.Ego

'I am sick.'

(4) nòmo=ki [nà nà-ti yè] làp-ku dù sister $=$ ERG [1sG be.ill-PFV COP.EGo] say-PST COP.PE

'sister ${ }_{i}$ said " $\mathrm{I}_{\mathrm{i}}$ am sick".' (AL 101013-02)

(5) nòmo [nà-ti yè] làp-ti làp-ku dù

sister [be.ill-PFV COP.EGo] say-PFV say-PST COP.PE

'sister ${ }_{i}$ said she $_{i}$ is sick' (AL 101013-02)

Because there are some elements of the utterance that undergo a deictic shift (e.g. the pronoun) but not others (e.g. the epistemic value of the copula) Tournadre (2008:300-301, see also Tournadre \& Dorje 2003:214-216) refers to this type of construction as 'hybrid speech'. Tournadre argues that the hybrid structure occurs when the agent is the same person in both the matrix clause and the reported speech clause, and would likely be expressed as pronouns. There is a general reluctance towards having two pronouns, especially when they would be coreferent. The use of the egophoric with a third person may be enough of a diagnostic for hybrid speech in Standard Tibetan, where the scope of what can occur with the egophoric is much more delimited (see Tournadre 2008). In Lamjung Yolmo the scope is much broader, and can include third person subjects (see Gawne 2014). Gyalrongic languages with person marking on the verb make this even more clear (see, for example, Jacques \& Antonov 2014)

6. In this paper complement clauses are given in square brackets. Phrases with an RS particle are not marked in this way as the particle does not create a complement clause in the way the $\mathrm{VoS}$ does. This is discussed in more detail throughout the paper. 
Similar strategies have been noted for Sherpa (Schöttelndreyer 1980: 126-129) and Kathmandu Newar (Hargreaves 2005:16-17), indicating that it may not be an uncommon strategy in Tibeto-Burman languages. As I discuss below there are some genres in which such hybrid indirect speech forms may not be particularly common.

In (5) not only is there a non-direct reported speech construction, but also a repetition of the VoS. This is not uncommon in elicited language, although it is much less frequent in more spontaneous speech, for example it does not occur in SBL's telling of the Family Story (101124-03), AL \& SL's telling of the family story (091108-01) or RL's telling of the Jackal and Crow (101010-01), both of which contain many reported speech events. In this structure the first of the two always has the perfective aspect suffix, which also functions as a clause chaining device. A similar VoS structure has also been observed in Dolakha Newar (Genetti 2007: 422).

In naturalistic speech the $\mathrm{VoS}$ is sometimes moved from the clause-final position to before the reported speech content (6).

(6) lùndi làp-sin [khé lú nèn cée yè] jackal say-PST [2sG song sing know COP.EGo]

'the jackal said "you know how to sing a song."' (RL 101027-01 02:14)

This strategy is not particularly common, however it is possible, while there are no examples of people being able to do this with the reported speech particle.

There are no examples in the Lamjung Yolmo corpus of this construction occurring with any other verbs, although Hari (2010:92) gives an example with the verb tii 'ask'.

One final thing to note about reported speech constructions in Lamjung Yolmo is that participants within the reported speech frame are often not expressed, especially if apparent from context. In narrative, often the speaker is not expressed, and if the any of the referents in the reported speech are also clear from context this will not be made explicit either, as seen in (7). SBL is telling The Family Story from the perspective of one of the participants; in the first utterance he overtly makes reference to the fact he is talking from the perspective of the man, and in that context it becomes unnecessary to mark this again in immediately afterwards in (8).

(7) nà tchán thún-di tcíiran dò-kandi 1sG alcohol drink-PFV only go-NOM 'after drinking alcohol, I go alone.' (SBL 101124-03 28:00)

(8) [tàpse òn-ke] làp-pa-ni

[now come-NON.PST] say-PST-FOC

““(I) am now coming” (I) said.' (SBL 101124-03 28:03) 
The VoS làp-also means something more like 'to speak' or 'to talk' in regard to a particular language (9).

(9) mò=ki khása tám làp khú yè

3sG.F=ERG Nepali language speak can COP.EGO

'she can speak Nepali language.' (AL 100930-01)

In Melamchi Valley Yolmo the VoS is má-, with làp- being used "in very restricted contexts" (Hari and Lama 2004: 448). The only example given in Hari and Lama's dictionary of làp- is in the sense of "to talk language to someone" so it does not appear, from this information at least, that it can be used as a VoS as per constructions such as (2)-(8), but it does share the usage in (9).

To give an idea of the range of RS strategies people use in interaction, I analysed all usage by a single speaker (SBL) in a 34 minute 40 second recording of the Family Story task. I chose this recording as the narrative involves people interacting and speaking to each other. There were 51 uses of the verb làp; 24 were in the sense 'to speak', and one was in the complex construction tcípe làpna meaning 'because' (likely a calque from Nepali kina banne 'because'). The remaining 26 tokens of làp were used in reported speech constructions. No other verb was used for reported speech constructions. None of the uses of the VoS were dislocated to the left edge of the embedded clause as in (6) above, and no example employed the double VoS as in (5). The majority of reported speech forms were direct reported speech, perhaps because the genre of narrative requiring a degree of immediacy, such as in (10).

$$
\begin{aligned}
& \text { nà tàpse òn-ran òn-ke làp-ti } \\
& \text { 1sG now come-EMPH come-NoN.PST say-PFV } \\
& \text { “"I am now coming” (he) said' (SBL 101124-03 06:51) }
\end{aligned}
$$

The difficulty is that there are a number of utterances where there is elision of the agent and/or patient in the embedded reported speech clause. There were two uses of the RS particle, indicating that for this speaker, in this genre, it was not the preferred way to construct reported speech. Bringing this approach to a wider range of collected data may yield more insights into preference for certain constructions in particular contexts. Unfortunately that is beyond the design of the current corpus, and scope of this paper.

\section{The reported speech particle}

Having established the structure of utterances with a VoS in Lamjung Yolmo, I now turn to the RS particle and its use. I discuss the structure of utterances that use the 
RS particle, and the broad functional parameters of the RS particle in (\$4.1). I then demonstrate in $\$ 4.2$ that what counts as 'speech' to be reported with this evidential form fits more broadly with the idea of interactional turns than specific verbal utterances. Finally in $\$ 4.3 \mathrm{I}$ look at the pragmatic effect of using the reported speech particle and argue that instead of weakening the speaker's commitment to the utterance it strengthens the content by invoking the knowledge of the quoted party.

\subsection{RS particle constructions}

There are several differences between structures with the VoS and those with the RS particle. The original utterance in (11) is a recording that was played for RL and (12) is his reporting of this using the RS particle. The pronoun is deictically reoriented, from the speaker in the first utterance to the speaker in the second utterance. The epistemic value of the copula, however, does not change. In these regards constructions with the RS particle look similar to the VoS hybrid speech construction discussed in $\$ 3$.

(11) nà sà tè-ti yè

1 SG eat AUX-PFV COP.EGO

'I am eating.' (AL 100930-01)

(12) mò sà tè-ti yè ló

3sG.F eat AUX-PFV COP.EGO RS

'she is eating (she said)' (RL 120218-01)

There are some differences with the VoS. First, the particle does not take verb inflection such as tense or aspect. It is a stand-alone particle that does not attach to the preceding content, as evidenced by the fact it has its own tone value (suffixes and clitics do not take tone). Second, the original speaker is never overtly referenced but is instead inferred from context. As I discuss below, the RS particle is used in contexts where the original author of the utterance can be determined. Finally, the RS particle is always final. Although most of the examples of the VoS above have the verb in the final position in the clause, as is the usual word order, this is not always the case. As shown in (6), in naturalistic speech it is possible for the VoS to precede the reported speech. Although this is a common strategy for $\mathrm{VoS}$ in naturalistic data it never occurs with the RS particle, which is always

7. One reviewer suggested that the lack of ergative on mò in this example may be one good indicator for ló being classed as a particle instead of a verb. Ergativity in Yolmo is not an obligatory marking, and so this cannot be used as definitive evidence that the reported speech marker is a particle instead of a verb. See Gawne (forthcoming) for more discussion of ergativity in Lamjung Yolmo. 
utterance-final. With these differences, the RS particle functions as an evidential particle rather than a verb of saying.

In these regards, the RS particle in Lamjung Yolmo already appears to demonstrate some structural differences with cognates in closely related varieties. In Kyirong (Huber 2005: 182) the reported form is a sentence final clitic that attaches to the final verb, and in a narrative it will attach to a VoS. In Melamchi Valley Yolmo the person who is the origin of the reported speech is usually mentioned (Hari 2010:62), which is not the case for any standard usage of the same form in Lamjung Yolmo that I have observed. This degree of variation of cognate forms within closely related languages indicates that even though the function of reported evidential forms across languages may be similar, there is still a great deal of variation.

While the RS particle has the function of quoting the speech of others, this does not mean that the use of the RS particle is compulsory. There are many instances where speakers can use a VoS, or just repeat the information that is reported. Therefore, it is a choice of the speaker, and not a compulsory requirement, to mark speech as reported. This means that the listener cannot assume that because something is not marked with an RS particle (or a VoS) then it is not something that is being reported. This is different to a system like Tariana (Arawak) (Aikhenvald 2004:3) where it is a grammatical expectation that all reported speech is marked as such.

The RS does not sit grammatically within the copula verb or auxiliary verb paradigms, where the other evidential forms are located. Instead, it occurs on the matrix level of the reported speech clause, separate to the modal value of the copula within the original utterance. The majority of examples in this paper use the perceptual evidential (PE) dù and various egophoric (EGO) forms (yè, yèke and yimba), which are the most common evidentials, however the RS particle can occur with any evidential as long as it was part of an utterance that is being reported. Therefore, the RS particle is part of a larger system of evidentiality across the language. This demonstrates that evidentiality is not a single simple category. In the same way that the copula verb series includes the dubitative epistemic forms yindo and yèto, the evidential distinctions are located in both the copular series and this separate particle. Using a particle to indicate reported speech as the source of information allows it to combine with original utterances that include access to information (as per observations of Tournadre \& LaPolla 2014), be it egophoric, perceptual or general fact. Examples given are predominantly with affirmative forms of the copulas, although it is equally possible to use the negative equivalents.

The RS particle does not interact in any specific or unexpected way with the value of the copula being reported. The evidential copula has scope over the original utterance and the RS particle has scope over the whole utterance. This is not the case in all languages with a reported evidential form. For example, Aikhenvald 
(2004: 83-84) observes that in Tsafiki (Arawak) the reported evidential can occur with the other evidentials to specify "the source of information the original speaker had." Unlike Lamjung Yolmo, though, it can occur without another evidential, similar to what was discussed for Kyirong above (Huber 2005: 182).

There is an expectation that if a person observed an event, and also heard about it, that they would use the perceptual evidential rather than the RS particle. Likewise, if two people report on an even and one uses a perceptual evidential and the other an RS particle, then the person who used the perceptual would be considered to have more direct information (RL 101030-05). According to RL, as well as my own observations, the RS particle is generally considered to mark a more reliable source of information than a dubitative construction. The preference between the egophoric and the RS particle is not quite as clear for speakers. RL suggested the difference between them was minor, however the egophoric has a wider range of contextual uses, including being used to mark actions of others that are known to be habitual.

The utterance always reorients to the person doing the reporting. This can be difficult to determine in some contexts, but it is apparent in utterances with deictic elements, as these always reorient. If a child said (13) to their mother, the woman could report to her sister what her child said to her using a construction such as (14).

(13) yíbi ò̀-ke

grandmother come-NON.PST

'grandmother is coming.' (RL 091108-01)

(14) áma òn-ke ló

mother come-NON.PST RS

'mother is coming (she said).' (RL 091108-01)

This reorientation of deictic information demonstrates that the RS particle is not intended as a verbatim quote marker, but to give the salient content of the original utterance, and to indicate that the speaker of the information is not the originator. The fact that the RS particle is not used to report your own speech back to someone further indicates that the information is being flagged as reported, and not the speaker's own.

We also see this in the way the reported speech can be then further transferred. If the woman reported (14) above, and her sister wanted to subsequently pass on the information to another party something like (15) would be ungrammatical.

\author{
(15) *áma òn-ke ló ló \\ mother come-NON.PST RS RS \\ *'mother is coming (she said she said)'. (RL 101123-02)
}


Reported speech markers are not embedded in this way; instead she would use a construction with a single RS particle, such as (11) above. Like with the shifting deixis above, this indicates that is it not important that the original message is respoken exactly the same, but that the main content of the message is transferred. It also indicates that it is the content of the reported speech, and not the originator that is of prime importance in these constructions, as the originator of the speech is no longer clear in the repeated utterance.

It does not appear to be common to use the RS particle to quote something back to the originator of the utterance. I only have one spontaneous example of this (16), where RL ask SNL to confirm something she said earlier while they were playing twenty questions:
úu phérti mì-ti yè ló
breathe NEG.NON.PST-(breath) COP.EGO RS
'(it) breathes, exists (you said).' (RL 101120-02 09:11)

The only time an RS particle is regularly directed back to a speaker is in interrogative constructions, which I discuss with regard to examples (21-24) below.

It is also possible for a person to use the RS particle for their own speech, if that speech is reheard on something like a recording or read out from a letter, as in (18), where RL listened to a recording of his own voice from an earlier elicitation session (17) and then repeats what he heard using a RS particle construction (18). ${ }^{8}$

$$
\begin{aligned}
& \text { (17) yà nàl tè-ti } \\
& \text { 1sG sleep AUX-PFV } \\
& \text { 'I am sleeping' (RL 101026-02) } \\
& \text { (18) yà nàl tè-ti yè ló } \\
& \text { 1sG sleep AUX-PFV COP.EGO RS } \\
& \text { 'I am sleeping (I said)' (RL 120218-01) }
\end{aligned}
$$

Similar observations have been made about use of evidentials that are usually infelicitous with first person (such as perceptual evidentials) in situations like recordings (e.g. Garrett 2001: 166 for Standard Tibetan), but this is the first time it has been demonstrated for reported speech evidentiality. The addition of the copula in the quote means that RL is supplying additional information in the quote that was not in the original utterance. I describe this in more detail in the discussion of reporting incomplete utterances in $\$ 4.2$.

8. The fact that the pronoun did not reorient does not mean it is a direct speech structure, but simply indicates that he is aware he is quoting his own, previous, speech and as such there is no deictic reorientation of the pronoun needed. 
There appears to be a preference for using the RS particle over the VoS for recent speech events. In sessions with both AL (120208-01) and RL (120218-01) I played them various sentences that I had elicited from different sessions. I would then ask them either tcí láppa? or tcí ló? ('what did (she/he) say?') with the VoS or RS particle respectively). Both speakers showed strong preference for repeating the speech with the RS particle, even when I asked them tci làppa? using the VoS such as in (19).

(19) khí tó sà-teran yèke ló

dog rice.cooked eat-IPFV COP.EGO.PST RS

'the dog was eating rice (he said).' (AL 120208-01, RL 120218-01)

This preference for the RS particle was also something that I observed while transcribing sections of the Family Story (101123-04) with ST. Often ST would listen to something said by the participants and then repeat it to me with the RS particle. RL's (101027-03) intuitions about the preferred use of the RS particle supported this. He felt that it was most appropriate for situations where a person was still present after making the original utterance. If the original speaker were on the telephone he felt that it would be acceptable to use the RS particle, but only if they are still on the line.

In (16) and (19) we saw speech being reported only a few minutes, at most, after the original utterance, but the time span between the original utterance and report can be much longer than indicated by speakers' intuitions. Example (20) is from a conversation I participated in with some Lamjung Yolmo speakers from one of the more isolated villages. During a discussion about who was related to whom in the village, one of the older people wanted to know about my family. We were talking in Nepali and one person asked $b \bar{a}$ àmā hunuhuncha? ('are your mother and father alive?'), to which I replied hunuhuncha, ('they are'), and KL supplied the man with additional information, in Lamjung Yolmo:

(20) mème yíbi yè ló

grandfather grandmother COP.EGO RS

'grandfather and grandmother are alive (she said).' (KL 21/11/2011 book 4: 46)

There are two things to note about this example. The first is the duration of time since the original utterance. The information $\mathrm{KL}$ is reporting about my grandparents is something I told her at least 4 weeks earlier. In discussions about the use of the RS particle, speakers are reluctant to say that they would mark reported speech beyond a relatively short duration of time. In one conversation RL thought that maybe a week would be acceptable, but only for some particularly salient and stable information (101027-03). This example shows that speakers are able to report particularly salient information many weeks after the original utterance, 
a longer time span than speaker intuitions indicate. The second thing to note is that the information was originally given to KL by myself in Nepali (our default communication language). This translation of Nepali into Yolmo in RS particle constructions is discussed in $\$ 4.2$ in more detail.

The RS particle can also be used as a question-asking strategy, in which RS particle is used with an interrogative pronoun. The most common construction of this type is (21).

(21) tói ló

what RS

'what (did you say?)' (RL 101120-01)

The person asking this question desires the utterance to be repeated, and the request can be either directed at the person who made the original utterance, or another person who is present. Unlike declarative constructions using reported speech, where directing the RS particle back at the original speaker like in (16) is uncommon, this interrogative use of the RS particle is quite often directed back at the original speaker. Huber $(2005: 182)$ notes that this form is also frequently used in Kyirong for two functions: when a speaker did not hear what was said, and when trying to remember a certain expression. The second use is also a valid use in Lamjung Yolmo, based on my observations, but the examples I have in my corpus are all relating to a specific utterance that the speaker did not hear.

The question does not have to cover the whole utterance, but only a component of the utterance. Example (22) is the original utterance, and the questions in (23) and (24) have different scope in relation to the original utterance, which then yield different answers.

(22) áma òn-ke

mother come-NON.PST

'mother is coming' (AL 120311-01)

(23) sú ló

who RS

'who (did she say)?' (AL 120311-01)

áma ló

mother Rs

'mother (she said).' (AL 120311-01)

(24) sú òn-ke ló

who come-NON.PST RS

'who is coming (did she say)?' (AL 120311-01) 
áma òn-ke ló

mother come-NON.PST RS

'mother is coming (she said).' (AL 120311-01)

When asking a question of the original speaker, their reply does not include an RS particle for their own utterance, however when asking about a third person's speech the RS particle is generally included.

One domain that I have not mentioned is narrative. Reported speech forms in Tibeto-Burman languages are often noted to occur as part of narratives (Goldstein and Nornang 1970, Höhlig 1978, Matisoff 1982:377, Hongladarom 2007). In closely related Tibetic varieties the RS particle is discussed as occurring frequently in narratives. In Kyirong narratives the reported form will attach to the VoS (Huber 2005: 182). Hari (2010:92) gives several examples of the RS particle being used in narratives in Melamchi Valley Yolmo, and in my own work with Kagate I have observed that the cognate reported speech particle occurs in narratives. Below are some examples from Kagate: ${ }^{9}$
lùndi gik phrétu ló
jackal one arrive-IPFV RS
'a jackal came.' (PML 101125-01 01:36)
(26) nà-i tábu ká làp dù ló
$1 \mathrm{SG}=\mathrm{ERG}$ horse part say COP.PE RS
“"that's my horse!" he said.' (PML 101125-01 04:32)

I have not observed any consistent use of the RS particle in narratives in Lamjung Yolmo. Given that so many closely related varieties use cognate reported speech evidentials in narratives, it is likely that Lamjung Yolmo is the variety that has lost this function, rather than the others all innovating it. This may be because Lamjung Yolmo speakers exhibit lower rates of oral narrative transmission than speakers of other varieties, a loss of a domain of usage that correlates with its generally declining transmission to younger speakers. Alternatively, or perhaps concurrently, there has been a narrowing of the function to specific interactional events.

There is a small set of examples that do not pattern like those presented so far. These examples relate to the general fact copula òge. This evidential is an unusual form that does not occur in Kyirong or other related Tibetic varieties, and can only be used in constructions relating to generally known current facts. For historical facts, such as dinosaurs being large, it would be inappropriate with the general fact copula since that fact is no longer current. While it would be possible to just

9. These Kagate examples are from the corpus http://catalog.paradisec.org.au/collections/SUY1 
use a regular past tense construction, in elicitation discussions speakers also gave sentences like (27) and (28) as an alternative.

(27)

dinosaurs tchómbo yèke ló
dinosaurs(Eng) big COP.EGo.PST RS
'dinosaurs were big.' (RL 101125-01)

(28)
kàpu yàabu yèke ló
old.animate good COP.EGO.PST RS
'the old man was good.' (VL 101224-01)

The speakers appear to include the RS particle to capture the fact that this is not just their opinion, but that of others as well. This appears to act much more like a hearsay evidential, where deictically the form does not point back to a specific speech event but to the fact that the speaker knows this information through repetition from multiple sources. When I asked RL if the RS particle could be used instead of the general fact copula in a situation where the fact was still current he said that this was not an appropriate use of the RS particle and that the general fact copula should be used. As the only examples of these in my corpus occur in specific elicitation contexts it is possible that speakers only use the RS particle in this context to fill the gap left by the general fact copula for facts from the past.

\subsection{The nature of reported speech events}

The RS particle is used in repeating the speech of another person, therefore an utterance marked with the RS particle is always embedded in the context of an interaction across multiple turns. Many of the examples discussed above are elicited, or from very structured interactional contexts that involve full spoken utterances in Lamjung Yolmo. In this section I draw on examples that demonstrate that a broader understanding of what constitutes speech as reported in interaction. Below I explore the truth-value in the use of the RS particle, and then give examples of the RS particle being used to report incomplete speech, failed speech, translated speech and non-verbal speech events.

It is possible to use the RS particle to falsify a reported utterance. Examples I have seen of this indicate that these falsifications are usually to humorous rather than malicious ends. One example of this is (29), which was at a wedding. Alcohol was being passed around and when it reached me the woman next to me who knew I was a teetotaller said laughingly:

tchán thún-ke yè ló

alcohol drink-NON.PST COP.EGO RS

'she drinks alcohol (she said)' (woman1, 31/01/2011 book 8: 6) 
The woman's tone meant that the utterance was not to be taken seriously, but was poking fun at my dispreference for drinking at a social event like a wedding where drinking is the norm. Thus it should be remembered that just because the RS particle is used for reporting speech, doesn't mean that it is always true that that particular speech event occurred.

Beyond obvious jesting and fictitious utterances, there are examples where speech that is incomplete or incorrect is reported in a way that is modified from the original. (30) is a question that I was asked by KL. I attempted to respond (31), but what I said was not considered a grammatically appropriate response by KL, instead in (32) she corrected my attempt to the answer form she was expecting, and also included a RS particle.

(30) rò tóo-pa

friend hungry-PST

'(are you) hungry friend?'

(31) * mè-tóo

NEG.NON.PST-hungry

'(I'm) not hungry.'

(32)

mà-tóo yè ló

NEG.PST-hungry COP.EGO RS

'(you) are not hungry (you said).' (KL, 20/11/2010 book 4: 45)

KL has used the RS particle, not to indicate what I did say, but to indicate what I should have said. It may be that this use of the RS particle is an unusual innovation that KL used to manage interaction with a non-proficient speaker of Lamjung Yolmo, but it indicates that the RS particle is less about being a verbatim quote marker and more about capturing the intended meaning of the utterance. It is also used here as a politeness strategy by $\mathrm{KL}$, to indicate that she is not telling me whether I am hungry or not, but to indicate that she is quoting my intended words.

Sometimes it is not clear whether something has actually been said before it is framed as a reported speech event. For example, while KL and CL were describing optical illusions they were looking at a photograph of what looked like a swan, but was actually a hand painted as a very realistic bird. They had been saying it is a bird and I had been rejecting their suggestions, but had not yet told them what the image was. ST was also in the room, having completed the task with me earlier in the day, and attempt to help them along in (33).

(33) yàabu pè-ti tá-toy ló

good do-PFV look-IMP RS

'look at it well (she said).' (ST 120304-02 06:00) 
There is no one else but myself to whom that RS particle could be referring to in this interaction, but I had said nothing of the sort during this session, nor did I make such request or suggestion while looking at the image with ST (120304-01). I did, however, help ST to see that it was a hand and not a swan or duck and it appears that she is reporting what was, at most, an implicit motivation I was trying to achieve and never a direct utterance of mine. It may be that ST felt this is something like what I said, or should have said, during our earlier interaction. The reported speech particle here indicates that it is not her own request but someone else's (i.e. mine).

We also see the RS particle giving information beyond what was explicitly said in a context where a Nepali utterance is reported in Lamjung Yolmo. In these elicited examples I gave the speaker a Nepali utterance and asked how they would report this speech using the reported speech marker. These utterances involved selecting a copula verb as part of the information being reported. The copulas also include evidential or epistemic information, but the Nepali forms do not; this meant that speakers had to choose a value that was not present in the original utterance. Speakers had very strong ideas about which Lamjung Yolmo copula would be the appropriate choice in such situations. For example, if someone said in Nepali àmā gharma cha ("mother is in the house"), an utterance with no information about source of information, then speakers would report this in Lamjung Yolmo as in (34), and reject the use of the perceptual evidential as a valid report of the utterance, such as in (35).

(34) áma khím=la yè ló

mother house $=$ LOC COP.EGO RS

'mother is in the house (she said).' (RL 110129-01, AL 110215-01)

(35) *áma khím=la dù ló

mother house $=$ LOC COP.PE RS

'mother is in the house (she said).' (RL 110129-01)

As we saw in $\$ 4.1$, utterances marked with the RS particle maintain the copula value from the original utterance, even though deictic information shifts. Here, a speaker is translating from a language where the copula has no evidential val$\mathrm{ue}^{10}$ (Nepali), and in reporting the information they also report what they assume would be the evidential value of the copula form if the utterance were in Lamjung Yolmo. The choice of copula translating from Nepali to Yolmo in RS constructions

10. Of course, there is the matter of the copula form rahechha in Nepali, which some analyse (such as Peterson 2000:17) is glossed as a mirative/result-inferential evidential. In this set of elicitation all forms given in the initial Nepali utterances were either chha or hunuhunchha, which are both evidentially neutral. 
appears to be predominantly based on the general pattern of which copula is expected in a given context.

This is not just a case of speakers translating all Nepali copula forms into the egophoric copula as a default, as the perceptual evidential is found when we would expect a Lamjung Yolmo speaker to use it, as in (36). In (36) the Nepali utterance was khānā mitho cha ("food is tasty"). This is the same copula form as the example above (cha), which was translated into the egophoric evidential, but is the kind of sensory-evidence based context where a speaker of Lamjung Yolmo would use a perceptual evidential, which is exactly what we find.

(36) tó cìmbu dù ló

rice.cooked tasty COP.PE RS

'rice is tasty (it is said).' (AL 110215-01)

In these examples then, speakers of Lamjung Yolmo are reporting more than the original utterance, as their translation into their mother tongue from Nepali also includes an evidential value that was not grammatically present in the original utterance. These examples again demonstrate that the RS particle is not about verbatim quotation, but attempting to capture the intention of the other person's communicative act.

The speech event that is reported doesn't even have to be a verbal utterance. In the example below, an emblematic gesture that represented an interactional turn is reported using the RS particle. In a general conversation, a woman asked the group if any of us had change for a thousand rupee note. When KL looked at me I shook my head to indicate that I did not. She then reported this as (37) to the other woman.

(37) mè

ló

COP.EGO.NEG RS

'does not (she said).' (KL 07/03/2012 Book 4: 26)

RL (101027-03) also noted that the RS particle would be appropriate for quoting gestures, and written correspondence.

\subsection{The nature of reported speech events}

There are many examples where the RS particle in Lamjung Yolmo can be used in ways that do not appear to indicate an attitude or stance towards the reported content. There are also examples that appear to indicate that if there is any pragmatic information about speaker stance, it is that the speaker is using the RS particle to claim the authority of the reported party. As I observed in $₫ 2$, this is contrary 
to what is described in much of the literature, which assumes that reported or quotative evidential forms seek to distance the speaker from the reported content.

To return to the same wedding festivities as in (29), we see a non-jocular use of the RS particle (38). KL spoke to a person serving the meal, in reference to me:

$$
\begin{aligned}
& \text { cá mè-sà yè ló } \\
& \text { meat NEG.NON.PST-eat COP.EGO RS } \\
& \text { 'she doesn't eat meat (she said)' (KL 31/01/2011 book 8: 6) }
\end{aligned}
$$

To say this without an RS particle in Lamjung Yolmo would be to put words in another person's mouth. Here, KL is not using the RS particle because she doubts the truth of the utterance. She is well aware of this preference, and could have used a standard habitual construction without an RS particle. In choosing to use the RS particle KL validates the statement by indicating that it was not her own, and avoids the appearance that she is preventing the person serving from offering meat.

In (39) we see an example of a reported speech event during the optical illusion task from (33). KL and CL are looking at an image that could either be a landscape or a man's face. This is not a particularly easy illusion to see, and they were debating what was in the image. ST observed their confusion and was able to give them some advice (39), having completed the same activity earlier in the day.

(39) mì tònba òolegi-ni náasum=la mì dù ló person face and.then-FOC nose $=$ LOC person COP.PE RS 'a person's face, and then on the nose is a person (she said).' (ST 120304-02 08:15)

She also repeats the same assertion at 08:28 in the interaction. Because I had also recorded the session with ST (120304-01) it was possible to go back and listen to what I had said to her in that interaction. The quote in (39) is not something I said at any point in that interaction-but ST herself did say similar things at various points (40)-(41).

(40) mì tònba dì mì pú ràra án dù person face this person hair like also COP.PE 'a human face, this is also like human hair.' (ST 120304-02 08:17)

(41) mì náasum=la dù person nose $=$ LOC COP.PE

'a person is on the nose.' (ST 120304-02 08:31)

ST also used the RS particle at other points in the task, but for things that were identifiably my speech in the interaction. (39) is different because it is something she herself had said but is now quoting as a report. Although the RS particle is not used to report self-speech, it is possible that ST cannot recall that it was her own 
observation, but more likely she is simply attributing the validity of the utterance to someone else, in this instance, myself. This means that she can instruct her sister $(\mathrm{KL})$ and bother-in-law $(\mathrm{CL})$ during the task with greater authority.

It is not always easy to tell from context whether or not someone is using the RS particle to emphasize the validity of an utterance. Example (42) is another spontaneous utterance, in a situation where a group of people had walked from a distant village to one near the bus stop, and were waiting at a friend's house until the arrival of the next bus. AL had just been told by the friend at whose house they were visiting that there would be another jeep that day. When someone else asked whether a jeep was coming AL replied:

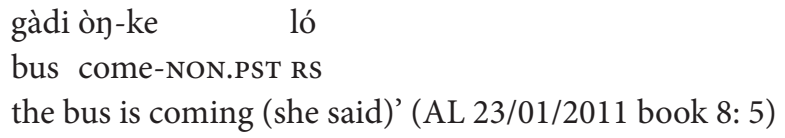

From the context alone it is not entirely clear whether AL is using the RS particle to show that there is authority behind her utterance, or whether she is using it to indicate that she is avoiding responsibility for the information in case the bus does not show up. It is possible that in different contexts the pragmatic effect of invoking authority with the RS particle may shift.

\section{Conclusion}

Aikhenvald (2004:31) argues in her typology of evidentiality cross-linguistically that " $[t]$ he reported evidential tends to be semantically rather uniform across languages." This is true in as much as these forms are all used to mark an utterance that reports content of an earlier speech act. A more detailed investigation of the interactional use of the RS particle in Lamjung Yolmo demonstrates that the nature of 'reporting' is actually a complex interactional turn, and can involve the reporting of incomplete, non-verbal and translated speech acts. Even cursory comparison with the brief descriptions of reported speech in other languages indicates that the function of the Lamjung Yolmo RS particle exhibits a degree of difference, even with cognates in closely related Tibetic varieties. The collection of more interactional data, and a more sensitive understanding of the function of these forms beyond just 'reporting speech' will allow for even deeper crosslinguistic comparison in the future. 


\section{Abbreviations}

1 first person, 2 second person, AUX auxiliary verb, COP copula, EGO egophoric, EMPH emphatic, ERG ergative, F female, FOC focus, GEN genitive, IMP imperative, IPFV imperfective, LOC locative, MIR mirative, NEG negative, NOM nominalizer, NON.PST non-past, PART particle, PE perceptual evidential, PFV perfective, PST past, RS reported speech, SG singular

\section{Acknowledgements}

Thank you to speakers of Lamjung Yolmo for giving me their time and sharing their language. Fieldwork and initial analysis was completed while I was a PhD candidate at The University of Melbourne. This work was in part funded by the Australian Research Council Discovery Project (0878126) "Language and Social Cognition: The Design Resources of Grammatical Diversity" and the Alma Hanson Scholarship at The University of Melbourne. Thank you to NTU, where I wrote an initial draft of this paper. Thank you also to people who gave feedback on earlier versions of this work, including Barbara Kelly, Rachel Nordlinger, Edward Garrett and David Hargreaves. Thank you to the two anonymous reviewers who gave this paper their thoughtful attention.

\section{References}

Aikhenvald, Alexandra Y. 2004. Evidentiality. Oxford: Oxford University Press.

Ameka, Felix K. 2004. Grammar and cultural practices: The grammaticalization of triadic communication in West African languages. Journal of West African Languages 30(2).5-28.

Anderson, Lloyd B. 1986. Evidentials, paths of change, and mental maps: typologically regular asymmetries. In Wallace L. Chafe and J. Nichols (eds.), Evidentiality: the linguistic coding of epistemology, 273-312. Norwood, N.J.: Ablex Pub. Corp.

Burling, Robbins. 1961. A Garo Grammar. Pune: Deccan College Postgraduate and Research Institute.

Caplow, Nancy J. 2000. The epistemic marking system of émigré Dokpa Tibetan. Unpublished ms. University of California. Santa Barbara. Retrieved from http://lingtechcomm.unt. edu/ njcaplow/

Chafe, Wallace L. 1986. Evidentiality in English conversation and academic writing. In Wallace. L. Chafe and Joanna. Nichols (eds.), Evidentiality: the linguistic coding of epistemology, 261272. Norwood, N.J.: Ablex Pub. Corp.

Daudey, Henriëtte. 2014. A grammar of Wadu Pumi. Melbourne: La Trobe University PhD dissertation.

Driem, George van. 1998. Dzongkha. Leiden, The Netherlands: Research School CNWS, School of Asian, African, and Amerindian Studies.

Garrett, Edward John. 2001. Evidentiality and Assertion in Tibetan. Los Angeles: University of California $\mathrm{PhD}$ dissertation.

Gawne, Lauren. 2013a. Lamjung Yolmo copulas in use: Evidentiality, reported speech and questions. Melbourne: The University of Melbourne PhD dissertation. 
Gawne, Lauren. 2013b. Notes on the relationship between Yolmo and Kagate. Himalayan Linguistics 12(2).1-27.

Gawne, Lauren. 2014. Evidentiality in Lamjung Yolmo. Journal of the South East Asian Linguistics Society 7.76-96.

Gawne, Lauren. Forthcoming. A sketch grammar of Lamjung Yolmo. Canberra: Asia Pacific Linguistics.

Genetti, Carol. 2007. A grammar of Dolakha Newar. Berlin; New York: Mouton de Gruyter. DOI: $10.1515 / 9783110198812$

Goldstein, Melvyn C. \& Nawang Nornang. 1970. Modern spoken Tibetan: Lhasa dialect. Kathmandu: Ratna Pustak Bhandar.

Hargreaves, David. 2005. Agency and intentional action in Kathmandu Newar. Himalayan Linguistics 5.1-48.

Hari, Anna Maria. 2010. Yohlmo Sketch Grammar. Kathmandu: Ekta books.

Hari, Anna Maria, \& Chhegu Lama. 2004. Hyolmo-Nepālì-An̆grejī śabdakośa (Yohlmo-NepaliEnglish dictionary). Kathmandu: Central Dept. of Linguistics, Tribhnvan University.

Höhlig, Monika. 1978. Speaker orientation in Syuwa (Kagate). In Joseph E. Grimes (ed.), Papers on discourse (Vol. 50), 19-24. Kathmandu: Summer Institute of Linguistics.

Hongladarom, Krisadawan. 2007. Evidentiality in Rgyalthang Tibetan. Linguistics of the TibetoBurman Area 30(2).17-44.

Huber, Brigitte. 2005. The Tibetan dialect of Lende (Kyirong). Bonn: VGH Wissenschaftsverlag. Jacques, Guillaume. 2014. A phonological profile of Cone. In Jackson T.-S. Sun (ed.) Phonological Profiles of Little-Studied Tibetic Varieties, 265-371. Taipei: Academia Sinica.

Jacques, Guillaume and Anton Antonov. 2014. Semi-direct speech in Rgyalrongic languages: Stau vs Japhug, paper presented at Syntax of the World's Languages VI, Pavia, September 10.

Jäschke, Heinrich August. 1881. A Tibetan-English Dictionary. London: Routledge \& Kegan Paul.

LaPolla, Randy J., \& Chenglong Huang. 2003. A grammar of Qiang with annotated texts and glossary. Berlin; New York: Mouton de Gruyter. DOI: 10.1515/9783110197273

Lee, Sung-Woo. 2011. Eastern Tamang grammar sketch. Dallas: Graduate Institute of Applied Linguistics $\mathrm{PhD}$ dissertation.

Lidz, Liberty A. 2007. Evidentiality in Yongning $\mathrm{Na}$ (Mosuo). Linguistics of the Tibeto-Burman Area. 30(2).45-87.

Maibaum, Anita, \& Esther Strahm. 1973. Jirel texts. In Austin Hale (ed.), Clause, sentence and discouse patterns in selected Languages of Nepal: V. 4 word lists, 177-300. Norman: Summer Institute of Linguistics.

Matisoff, James A. 1982. The grammar of Lahu (2nd ed.). Berkeley, California: University of California Press.

Matisoff, James A. 2003. Handbook of Proto-Tibeto-Burman: system and philosophy of SinoTibetan reconstruction. Berkeley: University of California.

Michael, Lev. 2008. Nanti evidential practice: Language, knowledge, and social action in an Amazonian society. Austin: University of Texas PhD dissertation.

Michael, Lev. 2012. Nanti self-quotation: Implications for the pragmatics of reported speech and evidentiality. Pragmatics and Society 3(2).321-357. DOI: 10.1075/ps.3.2.09lev

Michael, Lev. (forthcoming). The cultural bases of linguistic form: The development of Nanti quotative evidentials. In Randy J. LaPolla \& Rik De Busser (eds.), The shaping of language: 
The relationship between the structure of languages and their social, cultural, historical and natural environments. Amsterdam; Philadelphia: John Benjamins.

Mithun, Marianne. 1999. The languages of native North America. Cambridge, UK; New York: Cambridge University Press.

Morey, Stephen. 2010. Turung: a variety of Singpho language spoken in Assam. Canberra: Pacific Linguistics.

Mushin, Ilana. 2001. Evidentiality and epistemological stance: narrative retelling. Amsterdam; Philadelphia, PA: John Benjamins. DOI: 10.1075/pbns.87

Peterson, John. 2000. Evidentials, inferentials and mirativity in Nepal. Linguistics of the TibetoBurman Area 23(3).13-37.

Plaisier, Heleen. 2007. A grammar of Lepcha. Leiden; Boston: Brill.

Post, Mark W. 2007. A Grammar of Galo. Melbourne: La Trobe University.

San Roque, Lila, Lauren Gawne, Darja Hoenigman, Julia Colleen Miller, Stef Spronck, Alan Rumsey, Alice Carroll \& Nicholas Evans. 2012. Getting the story straight: Language fieldwork using a narrative problem-solving task. Language Documentation and Conservation $6.135-174$.

San Roque, Lila, \& Loughnane, Robin. 2012. The New Guinea Highlands evidentiality area. Linguistic Typology 16(1).111-167. DOI: 10.1515/lity-2012-0003

Schöttelndreyer, Burkhard. 1980. Persons markers in Sherpa. Pacific Linguistics A 53.125-130.

Simon, Walter. 1968. Tibetan "re" in Its Wider Context. Bulletin of the School of Oriental and African Studies, University of London 31(3).555-562. DOI: 10.1017/S0041977X0012556X

Sun, Jackson T.-S. 1993. Evidentials in Amdo Tibetan. Bulletin of the Institute of History and Philology 63(4).143-188.

Tournadre, Nicholas. 1991. The rhetorical use of the Tibetan ergative. Linguistics of the TibetoBurman Area 14(1).93-107.

Tournadre, Nicholas. 2008. Arguments against the concept of 'conjunct'/'disjunct' in Tibetan. In Brigitte Huber, Marianne Volkart and Paul Widmer (eds.), Chomolangma, Demawend und Kasbek, Festschrift für Roland Bielmeier, 281-308. Saale: International Institute for Tibetan and Buddhist Studies.

Tournadre, Nicholas, \& Sangda Dorje. 2003. Manual of standard Tibetan: Language and civilisation. Ithaca: Snowlion Publications.

Tournadre, Nicholas, \& LaPolla, Randy J. 2014. Towards a new approach to evidentiality: Issues and directions for research. Linguistics of the Tibeto-Burman Area 37(2).240-263.

DOI: $10.1075 /$ ltba.37.2.04tou

Watters, David E. 2002. A Grammar of Kham. Cambridge: Cambridge University Press.

Willett, Thomas. 1988. A cross-linguistic survey of the grammaticalization of evidentiality. Studies in language 12(1).51-97. DOI: 10.1075/sl.12.1.04wil

Zeisler, Bettina. 2004. Relative tense and aspectual values in Tibetan languages: a comparative study. Berlin; New York: Mouton de Gruyter. DOI: 10.1515/9783110908183

Zeisler, Bettina. 2012. Evidentiality and inferentiality: Overlapping and contradictory functions of the so-called evidential markers in Ladakhi (West Tibetan). Paper presented atthe Nature of Evidentiality conference, Leiden, June 14-16, 2012. 